\title{
Cellular Localization of Synaptotagmin I, II, and III mRNAs in the Central Nervous System and Pituitary and Adrenal Glands of the Rat
}

\author{
B. Marquèze, ${ }^{1}$ J. A. Boudier, ${ }^{1}$ M. Mizuta, ${ }^{2}$ N. Inagaki, ${ }^{2}$ S. Seino, ${ }^{2}$ and $M$. Seagar ${ }^{1}$ \\ ${ }^{1}$ INSERM U 374, Institut Jean Roche, Faculté de Médecine-Nord, 13916 Marseille Cedex 20, France and 2Division \\ of Molecular Medicine, Center for Biomedical Science, Chiba University School of Medicine, Chuo-ku, Chiba 260, \\ Japan
}

Three isoforms of synaptotagmin, a synaptic vesicle protein involved in neurotransmitter release, have been characterized in the rat, although functional differences between these isoforms have not been reported. In situ hybridization was used to define the localization of synaptotagmin I, II, and III transcripts in the rat CNS and pituitary and adrenal glands. Each of the three synaptotagmin genes has a unique expression pattern. The synaptotagmin III gene is expressed in most neurons, but transcripts are much less abundant than the products of the synaptotagmin I and II genes. A majority of neurons in the forebrain expressed both synaptotagmin I and III mRNAs while synaptotagmin II gene expression was confined to subsets of neurons in layers IV-VI of the cerebral cortex, in the dentate granule cell region, the hilus, and the CA1-CA3 areas of the hippocampus. In the cerebellum, all three transcripts were visualized in the granule cell layer. Furthermore, synaptotagmin I probes revealed striking differences between distinct populations of neurons, as in addition to moderate labeling of granule cells, much more prominent hybridization signals were detected on scattered cell bodies likely to be Golgi interneurons. In the most caudal part of the brain, synaptotagmin II transcripts were abundant and were coexpressed with synaptotagmin III mRNAs. This pattern was found in putative motoneurons of the spinal cord, suggesting that the two isoforms might be involved in exocytosis at the neuromuscular junction. Only synaptotagmin I mRNAs were detected in the anterior and intermediate pituitary and in adrenal medullary cells. These data reveal an unexpectedly subtle segregation of the expression of synaptotagmin genes and the existence of multiple combinations of synaptotagmin isoforms which may provide diversity in the regulation of neurosecretion.

[Key words: synaptotagmin, neurotransmitter release, mRNA distribution, CNS, pituitary gland, adrenal gland]

\footnotetext{
Received Oct. 27, 1994; revised Jan. 10, 1995; accepted Jan. 13, 1995.

We thank C. Iborra for her expert technical assistance, M. Grino for suggestions and precious help with tissue sections, and E. Jover and M. Takahashi for discussion and advice. We are grateful to J.-L. Boudier, F. Couraud, and A. Zamorra for their comments on the manuscript.

This research was supported by the Institut National de la Santé et de la Recherche Médicale (INSERM), France, and by the Scientific Research Grants of the Ministry of Education, Science and Culture, Japan.

Correspondence should be addressed to B. Marquèze, INSERM U 374, In stitut Jean Roche, Faculté de Médecine-Nord, Boulevard Pierre Dramard, 13916 Marseille Cedex 20, France.

Copyright (C) 1995 Society for Neuroscience $0270-6474 / 95 / 154906-12 \$ 05.00 / 0$
}

Structural, biochemical, and physiological data are consistent with a crucial role of synaptotagmin in neurotransmitter release (reviewed by DeBello et al., 1993). It is one of the major membrane components of synaptic vesicles (Matthew et al., 1981; Fournier and Trifaro, 1988) and is exclusively expressed in neurons and neuroendocrine cells. Synaptotagmin binds $\mathrm{Ca}^{2}$ at concentrations in the $10-100 \mu \mathrm{M}$ range in a phospholipid-dependent manner (Brose et al., 1992) and has been postulated to be the $\mathrm{Ca}^{2+}$ sensor which induces exocytosis.

Synaptotagmin interacts in vitro with multimolecular complexes which include syntaxin/HPC- 1 and the N-type $\mathrm{Ca}^{2+}$ channel (Bennett et al., 1992b; Lévêque et al., 1992, 1994; Yoshida et al., 1992), SNAP 25, synaptobrevin/VAMP (Söllner et al., 1993 ), the $\alpha$-latrotoxin receptor, and other related proteins of the neurexin family (Petrenko et al., 1991; Hata et al., 1993; O'Connor et al., 1993). These complexes are thought to be involved in synaptic vesicle docking at presynaptic active zones in close vicinity to the site of $\mathrm{Ca}^{2+}$ entry.

Furthermore, synaptotagmin may prevent assembly of the constitutive core machinery, formed by the association of N-ethylmaleimide-sensitive fusion protein (NSF) with soluble NSF attachment proteins (SNAPs), and its putative receptor: the VAMP, syntaxin, and SNAP 25 complex (Söllner et al., 1993). Also, synaptotagmin appcars to play a role in endocytosis through its interaction with the clathrin adaptor AP-2 (Zhang et al., 1994).

Drosophila mutants lacking synaptotagmin display a severe reduction of evoked neurotransmitter release and an increase in the frequency of spontaneous quantal events at the neuromuscular junction (Littleton et al., 1993; DiAntonio et al., 1994). In the giant synapse of the squid, injection of peptides from synaptotagmin into presynaptic terminals (Bommert et al., 1993) inhibits neurotransmission.

Synaptotagmin is expressed as variant isoforms encoded by different genes in the rat [synaptotagmin I (Perin et al., 1990); synaptotagmin II (Geppert et al., 1991); synaptotagmin III (Mizuta et al., 1994)]. The overall identity of amino acid sequence among them is relatively low; however, the region corresponding to the carboxyl terminal $\mathrm{C}_{2}$ repeats is well conserved. Synaptotagmin I and II are more closely related to each other than to synaptotagmin III. No functional differences have been reported between these isoforms.

Variations in sequence between synaptotagmins could lead to differences in docking and fusion providing fine tuning of regulated vesicular trafficking required for development and neu- 


\begin{tabular}{|c|c|c|}
\hline Probes & & Sequence \\
\hline \multicolumn{3}{|c|}{ Synaptotagmin I } \\
\hline Tgla & Complementary to bases $1800-1843$ & $\begin{array}{l}\text { TACTGGCTAAAGAGCACTATGTGGGCAGA- } \\
\text { TGCAGAAAGGCTTCG }\end{array}$ \\
\hline TgIb & Complementary to bases $2527-2571$ & $\begin{array}{l}\text { TGAAGCTATGCTAGATGCAGTGGTAGGAA- } \\
\text { CGCATTGGCTCCTGTT }\end{array}$ \\
\hline $\operatorname{TgIs}$ & Bases $1800-1843$ & $\begin{array}{l}\text { CGAAGCCTTTCTGCATCTGCCCACATAGTG- } \\
\text { CTCTTTAGCCAGTA }\end{array}$ \\
\hline \multicolumn{3}{|c|}{ Synaptotagmin II } \\
\hline TgIIa & Complementary to bases $1923-1966$ & $\begin{array}{l}\text { TTTCGCAAGGACTATGAGAGCTTCTGGCCT- } \\
\text { CTGACCACTTAAGC }\end{array}$ \\
\hline TgIIb & Complementary to bases $2447-2491$ & $\begin{array}{l}\text { AGTTGTGAGGAGCTCTGCAATGTCTAGCTT- } \\
\text { GTCACTGTCCACCAA }\end{array}$ \\
\hline Tglls & Bases 1923-1966 & $\begin{array}{l}\text { GCTTAAGTGGTCAGAGGCCAGAAGCTCTC- } \\
\text { ATAGTCCTTGCGAAA }\end{array}$ \\
\hline \multicolumn{3}{|c|}{ Synaptotagmin III } \\
\hline TgIIIa & Complementary to bases $1809-1853$ & $\begin{array}{l}\text { TTCTCTGACAATCCTTTGCCGCCCTTGGTA- } \\
\text { AAGCTGCTTAGAGTC }\end{array}$ \\
\hline TgIIIb & Complementary to bases $1853-1896$ & $\begin{array}{l}\text { GTCCAATCCCAGGCCTAGACCAGACCCTC- } \\
\text { ACTCTGAATTCTCTT }\end{array}$ \\
\hline TgIIIs & Bases $1809-1853$ & $\begin{array}{l}\text { GACTCTAAGCAGCTTTACCAAGGGCGGCA- } \\
\text { AAGGATTGTCAGAGAA }\end{array}$ \\
\hline
\end{tabular}

rotransmission. In order to analyze the distribution of the different isoforms, we have carried out an in situ hybridization study of the distribution of synaptotagmin mRNAs in the rat CNS and in the adrenal and pituitary glands.

\section{Materials and Methods}

Oligonucleotide probes. Oligonucleotide probes [44-45 base pairs (bp)] of unique sequence were synthesized (CIML, France) and purified by ethanol precipitation. The probe sequences derived from the rat synaptotagmin I (Perin et al., 1990), synaptotagmin II (Geppert et al., 1991), and synaptotagmin III (Mizuta et al., 1994) cDNAs are compiled in Table 1. Sense probes TgIs, TgIIs, and TgIIIs exactly complementary to TgIa, TgIIa, and TgIIIa antisense probes, respectively, were used as controls.

Probes were $3^{\prime}$-end labeled with $5^{\prime}-\left[\alpha-{ }^{35} \mathrm{~S}\right]$-dATP $(>1000 \mathrm{Ci} / \mathrm{mmol}$; Amersham) to similar specific activities in the range of $2 \times 10^{8}-1.4 \times$ $10^{\circ} \mathrm{dpm} / \mu \mathrm{g}$ using terminal deoxynucleotidyl transferase (Boehringer Mannheim) with a 30:1 molar ratio of dATP:oligonucleotide. Unincorporated nucleotides were removed by a spin column procedure using Sephadex G-25 (Pharmacia).

In situ hybridization. Nonperfused rat brains were removed and frozen on dry ice. Cryostat sections $(12 \mu \mathrm{m})$ were cut, mounted onto polyL-lysine-coated slides, and dried at room temperature. Sections were fixed in $4 \%$ paraformaldehyde, rinsed in phosphate-buffered saline (PBS), and dehydrated into $95 \%$ ethanol for storage at $4^{\circ} \mathrm{C}$, or dried and stored at $-80^{\circ} \mathrm{C}$ until required. Radiolabeled probe was dissolved in hybridization buffer $[50 \%(\mathrm{v} / \mathrm{v})$ formamide, $4 \times$ saline sodium citrate (SSC: $0.15 \mathrm{M} \mathrm{NaCl}, 0.015 \mathrm{M} \mathrm{Na-citrate),} \mathrm{and} 10 \%$ (w/v) dextran sulfate] in final concentrations of $0.14-0.5 \mathrm{nM}$ and applied to sections. Hybridization was performed at $42^{\circ} \mathrm{C}$ under a Parafilm cover. Sections were washed to a final stringency of $1 \times \mathrm{SSC}$ at $55^{\circ} \mathrm{C}$ and exposed to Kodak $\mathrm{X}$-Omat film at room temperature, or dipped in Ilford $\mathrm{K} 5$ emulsion. To examine the specificity of the signals observed, parallel sections were hybridized with two independent antisense oligonucleotides complementary to different regions of each transcript. Furthermore, control experiments were done with the sense oligonucleotide probes TgIs, TgIIs, and TgIIIs as detailed above. Some sections were also hybridized with the antisense probes in the presence of a large excess (50-fold) of the unlabeled oligonucleotide. The anatomy of sections and autoradiographs was determined using the atlas of Paxinos and Watson (1986).

\section{Results}

\section{Specificity of probes}

Probes to each of the three rat synaptotagmins produced unique patterns of hybridization in the rat brain (Figs. 1-5), spinal cord (Figs. 6, 7), and adrenal and pituitary glands (Fig. 8). Two probes, complementary to different regions of the same cDNA, were tested for each synaptotagmin. In each case, hoth members of the pair produced identical patterns of hybridization. No signal could be detected with the sense probes TgIs, TgIIs, and TgIIIs when used in the same conditions at equivalent specific activity (data not shown). Also, no labeling was observed on sections hybridized with radiolabeled TgIa and TgIIa in the presence of an excess of the unlabeled oligonucleotide (data not shown).

\section{In situ hybridization}

Macroscopic transcript distributions on sagittal and coronal sections of brain (Fig. 1), spinal cord (Fig. 6), and adrenal and pituitary glands (Fig. 8) are shown. Each probe produced regionally distinct hybridization signals. Regions of white matter such as the corpus callosum were devoid of synaptotagmin mRNAs. Cellular localizations of synaptotagmin transcripts were analyzed in different areas of the brain. While synaptotagmin I transcripts were confined to the most rostral part of the CNS, synaptotagmin II mRNAs were strongly expressed in spinal cord and brainstem. Synaptotagmin III mRNAs were weakly expressed throughout the nervous system. In the pituitary and adrenal glands synaptotagmin I transcripts were the major form.

The results are semiquantitatively summarized in Table 2. These data were compiled by evaluating both x-ray films (Fig. 1; see also Figs. 6, 8) and emulsion-coated slides (Figs. 2$5,7)$. 

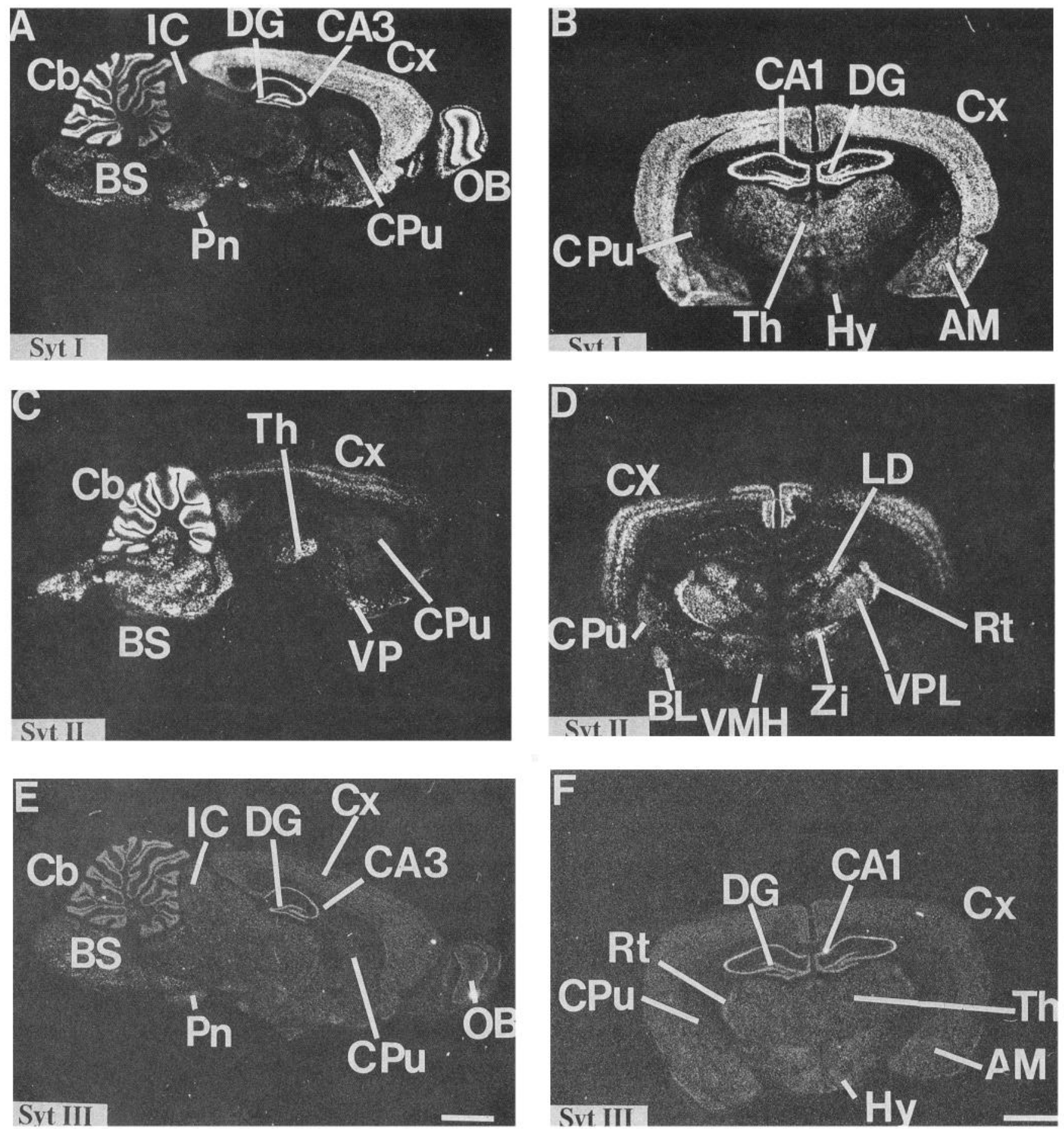

Figure 1. In situ hybridization of synaptotagmin I $(A, B ;$ syt $I)$, II $(C, D ;$ syt $I I)$, and III $(E, F ;$ syt $I I I)$ mRNAs in sagittal $(A, C, E)$ and coronal $(B, D, F)$ sections of rat brain. $A M$, amygdala; $B L$, basolateral amygdaloid nu.; $B S$, brainstem; $C b$, cerebellum; $C p u$, caudate putamen; $C x$, cortex; $D G$, dentate gyrus; $H y$, hypothalamus; $I C$, inferior colliculus; $L D$, laterodorsal thalamic nu.; $O B$, olfactory bulb; $P n$, pontine nu.; $R t$, reticular thalamic nu.; $T h$, thalamus; $V M H$, ventromedial hypothalamic nu.; $V P$, ventral pallidum; $V P L$, ventral posterolateral thalamic nu.; $Z i$, zona incerta. Exposure was on Kodak X-Omat film for 10 weeks. Scale bars: $A, C, E, 3.3 \mathrm{~mm} ; B, D, F, 2.4 \mathrm{~mm}$.

\section{Telencephalon}

Olfactory bulb. Only synaptotagmin I and III mRNAs were detected in olfactory bulb tissuc (Fig. 2). Strong labeling was obtained with the synaptotagmin I probe while synaptotagmin III hybridization was weak. In mitral cells synaptotagmin I-positive cells were heavily labeled (Fig. 2A). Transcripts specific for syn- aptotagmin I and III were observed in the internal granule cells, in tufted cells of the external plexiform layer, and in the glomerular cell layer (Fig. 2B,F).

Cerebral cortex. Autoradiographs (Fig. 1) showed that all three mRNAs are expressed in the cortex but display different distributions. Synaptotagmin I (Figs. $1 A, B ; 3 A$ ) and III (Figs. 
Table 2. Relative distribution of synaptotagmin I (Syt I), II (Syt II), and III (Syt III) mRNAs in different regions of the CNS and pituitary and adrenal gland of the rat

\begin{tabular}{|c|c|c|c|}
\hline Area & Syt I & Syt II & Syt III \\
\hline \multicolumn{4}{|l|}{ Olfactory bulb } \\
\hline Periglomerular & +++ & ND & + \\
\hline External plexiform layer & +++ & ND & + \\
\hline Mitral cell layer & $++t+$ & ND & $+t$ \\
\hline Internal granule cell layer & +++ & ND & + \\
\hline \multicolumn{4}{|l|}{ Neocortex } \\
\hline Layer II/III & +++ & ND & + \\
\hline Layer IV & +++ & ++ & + \\
\hline Layer V/VI & +++ & ++ & + \\
\hline \multicolumn{4}{|l|}{ Hippocampus } \\
\hline CA1 pyramidal cell layer & +++ & some cells ++ & ++ \\
\hline CA3 pyramidal cell layer & +++ & some cells ++ & ++ \\
\hline DG granule cells & ++ & some cells ++ & ++ \\
\hline \multicolumn{4}{|l|}{ Basal nuclei } \\
\hline Caudate putamen & + & + & + \\
\hline Globus pallidus & + & ++ & + \\
\hline \multicolumn{4}{|l|}{ Amygdala } \\
\hline Basolateral amygdaloid nu & ++ & ++ & + \\
\hline Central amygdaloid nu., lateral & ++ & ND & + \\
\hline Medial amygdaloid nu. & ++ & ND & + \\
\hline Medial habenula & ++ & ND & + \\
\hline \multicolumn{4}{|l|}{ Thalamus } \\
\hline Central medial nu. & ++ & ND & + \\
\hline Laterodorsal nu. & ++ & ++ & + \\
\hline Ventral posterolateral nu. & + & ++ & + \\
\hline Ventromedial nu. & ++ & ND & + \\
\hline Reticular nu. & ND & ++ & + \\
\hline Zona incerta & + & + & + \\
\hline Hypothalamus & + & + & + \\
\hline \multicolumn{4}{|l|}{ Colliculi } \\
\hline Inferior & ++ & ++ & + \\
\hline Superior & + & + & + \\
\hline \multicolumn{4}{|l|}{ Cerebellum } \\
\hline Molecular cell layer & + & +++ & ++ \\
\hline Purkinje cell layer & ND & +++ & $\mathrm{ND}$ \\
\hline Granule cell layer & $\begin{array}{l}+++ \\
\text { some cells }++++\end{array}$ & +++ & ++ \\
\hline Pons/medulla & + & ++ & + \\
\hline Pontine nu. & ++ & ++ & + \\
\hline \multicolumn{4}{|l|}{ Spinal cord } \\
\hline Dorsal horn & ++ & +++ & ++ \\
\hline Ventral horn & ND & +++ & ++ \\
\hline \multicolumn{4}{|l|}{ Pituitary gland } \\
\hline Anterior lobe & ++ & ND & ND \\
\hline Intermediate lobe & +++ & ND & $\mathrm{ND}$ \\
\hline Posterior lobe & ND & ND & ND \\
\hline Adrenal gland & $\begin{array}{l}++ \\
\text { some cells }+++\end{array}$ & $\mathrm{ND}$ & ND \\
\hline
\end{tabular}

In situ hybridization signals obtained with ${ }^{35}$ S-labeled oligonucleotide probes on sections were assessed as intense $(++++)$, strongly positive $(+++)$, positive $(++)$, weakly positive $(+)$, or not detectable (ND).

$1 E, F ; 3 C)$ transcripts were present in all areas and laminas explored of the cerebral cortex. Synaptotagmin I transcripts were the most abundant. Sparsely distributed cells displaying horizontally oriented perikarya situated in deep layer VI were strongly labeled with synaptotagmin I probes (data not shown). A restricted expression of synaptotagmin II mRNAs was found.
Synaptotagmin II transcripts were not detected in regions of the frontal (Fig. 1C) and perirhinal (Fig. 1D) cortex. On emulsiondipped slides, labeling was confined to a few cells of layer IV, pyramidal cells of layer V (Fig. $3 B$ ), and some neurons of layer VI.

Hippocampus. In the hippocampus, distinct patterns of hy- 

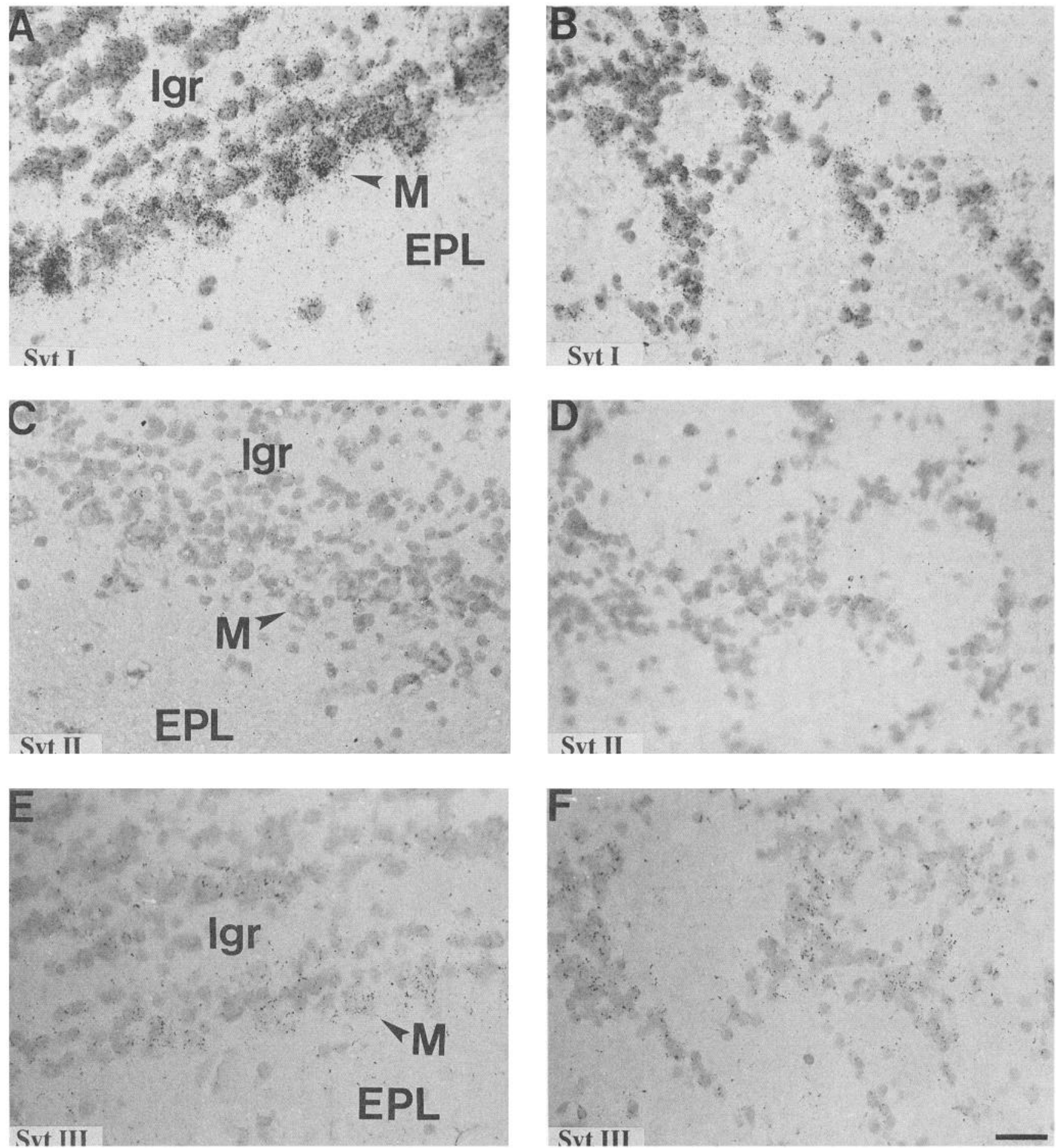

Figure 2. High-power bright-field photomicrographs of the olfactory bulb through the internal granular and mitral cell layers $(A, C$, $E$ ) and glomerular cell layer $(B, D, F)$ showing the distribution of synaptotagmin I $(A, B)$, synaptotagmin II $(C, D)$, and synaptotagmin III $(E, F)$ mRNAs. $I g$, internal granular layer; $E P L$, external plexiform layer; $M$, mitral cell layer. Exposure times of the emulsion-coated slides were 7 weeks $(A-D)$ and 10 weeks $(E, F)$. Scale bars, $30 \mu \mathrm{m}$.

bridization were again observed for the different transcripts. A strong hybridization signal was produced by synaptotagmin I probes in the CA1-CA4 areas and in the dentate gyrus (Fig. $1 A, B)$. Localization of transcripts at the cellular level is shown in Figure 4. Synaptotagmin I-positive CA3 cells (Fig. 4B) could be seen in addition to labeled granule cells in the dentate gyrus (Fig. 4A). The same pattern of expression was seen for synap- totagmin III, but transcripts were present in much lesser amounts (Fig. $4 E, F$ ). Sections hybridized with synaptotagmin II probes exhibited a confined pattern of labeling. Very few large neurons in the granule cell layer (Fig. $4 C$ ) and in the hilar region expressed the synaptotagmin II gene. Furthermore, a number of scattered cells in the CA4-CA1 pyramidal cell layer were also labeled (Fig. 4D). The frequency of cells expressing synaptotag- 

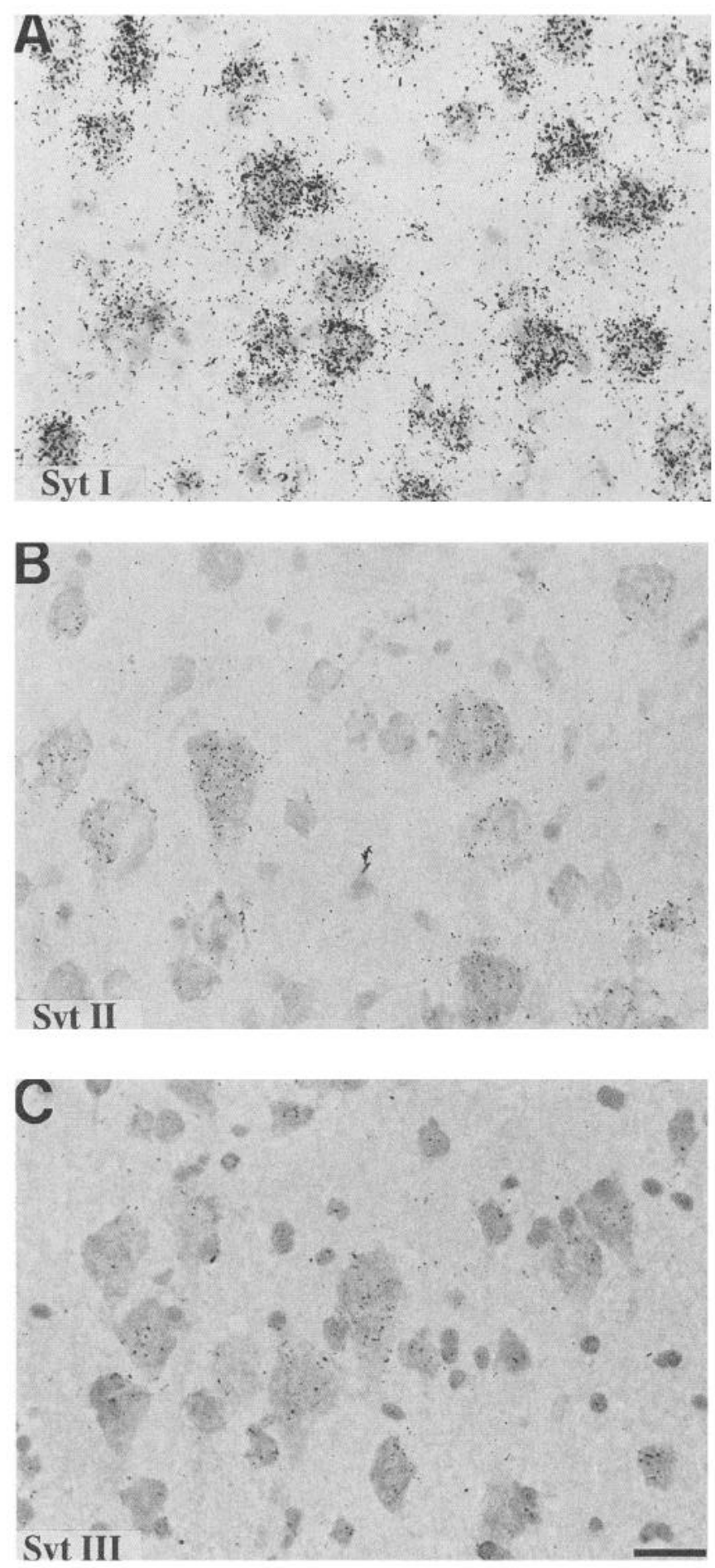

Figure 3. High-power bright-field photomicrographs of the cerebral cortex cell layer $\mathrm{V}$, showing the distribution of synaptotagmin I $(A)$, II $(B)$, and III $(C)$ transcripts. Exposure times were 7 weeks $(A, B)$ and 8 weeks $(C)$. Scale bars, $27 \mu \mathrm{m}$.

min II gene was low throughout hippocampus: around 10-25 cells per $12 \mu \mathrm{m}$ sagittal section cut in the same plane as in Figure $1 C$.

Amygdala. Synaptotagmin I- and III-positive cell bodies (Fig. $1 B, F$, respectively) were found in all nuclei of the amygdaloid complex. Synaptotagmin I transcripts were again the major form.
Hybridization to synaptotagmin II mRNAs was restricted to the basolateral amygdaloid nucleus (Fig. 1D).

Striatum. Cells of the caudate putamen contained low levels of synaptotagmin mRNAs. In the globus pallidus (Fig. 1D) and ventral pallidum (Fig. 1C) synaptotagmin II transcripts were present at a moderate level.

\section{Diencephalon}

Thalamus-hypothalamus. Characteristic distributions for each of the synaptotagmin transcripts were seen in the thalamus. Synaptotagmin I transcripts were abundant in most nuclei of the thalamus observed, but were not seen in the reticular thalamic nucleus (Fig. 1A,B). Low levels of synaptotagmin III mRNAs were also present throughout the whole thalamus (Fig. 1E,F). Synaptotagmin II transcripts were restricted to certain nuclei such as the ventral posterolateral nucleus and the zona incerta (Fig. 1D). The reticular thalamic nucleus exhibited strong signals. This area appeared to contain only one type of neuron. These cells are thus likely to express both synaptotagmin II and III mRNAs. The rest of the diencephalon did not show a strong labeling. Synaptotagmin I (Fig. $1 B$ ) and III (Fig. $1 F$ ) transcripts were ubiquitously expressed in the hypothalamus although at a low level. The three mRNAs were present in the ventromedial hypothalamic nucleus (Fig. $1 B, D, F)$.

\section{Metencephalon}

Cerebellum. Autoradiographs indicated that all of the transcripts were expressed in granule cells (Fig. 1A,C,E). Examination of sections exposed to photographic emulsion confirmed this observation (Fig. 5B,D,F). Furthermore, with synaptotagmin I probes, a subpopulation of neurons in the granule cell layer was more strongly labeled. These cells were scattered homogeneously in all granule cell layers in each lobule of the cerebellar cortex (Fig. 5B). It was not possible to determine the morphology of the positive cells but their frequency suggested that they were Golgi II cells (Shivers et al., 1986). Synaptotagmin I and III transcripts were not detectable in Purkinje cells (Fig. 5A,E, respectively). They were present most probably in the stellate/ basket cells of the molecular cell layer (Fig. 5A,E). Synaptotagmin II was widely expressed through all cell layers (Fig. 5C,D).

\section{Spinal cord}

We processed sections of the spinal cord at cervical (Fig. 6) and thoracic (data not shown) levels. Synaptotagmin I transcripts were restricted to the dorsal horn of the spinal cord, possibly in layers I and II (Fig. 6A). Some scattered positive cells were found in layers V-VII. Labeling in the intermediolateral nucleus was visible on thoracic sections. The cellular localization with emulsion-coated sections confirmed these results. Putative motoneurons were devoid of labeling (Fig. 7A), while some positive neurons were seen in the dorsal horn (Fig. $7 B$ ). Synaptotagmin II mRNAs were abundant throughout the entire spinal cord section (Fig. 6B), showing strong expression in large cells in the ventral horn, probably motoneurons (Fig. $7 C$ ), and in all cells of the dorsal horn (Fig. 7D). Synaptotagmin III mRNA distribution followed the same pattern (Fig. 6C), but the level of hybridization was lower (Fig. $7 E, F$ ).

\section{Endocrine cells}

Pituitary gland. The autoradiograph in Figure $8 A$ showed that synaptotagmin I transcripts were distributed throughout the anterior and intermediate lobe of the pituitary. Labeling was ho- 

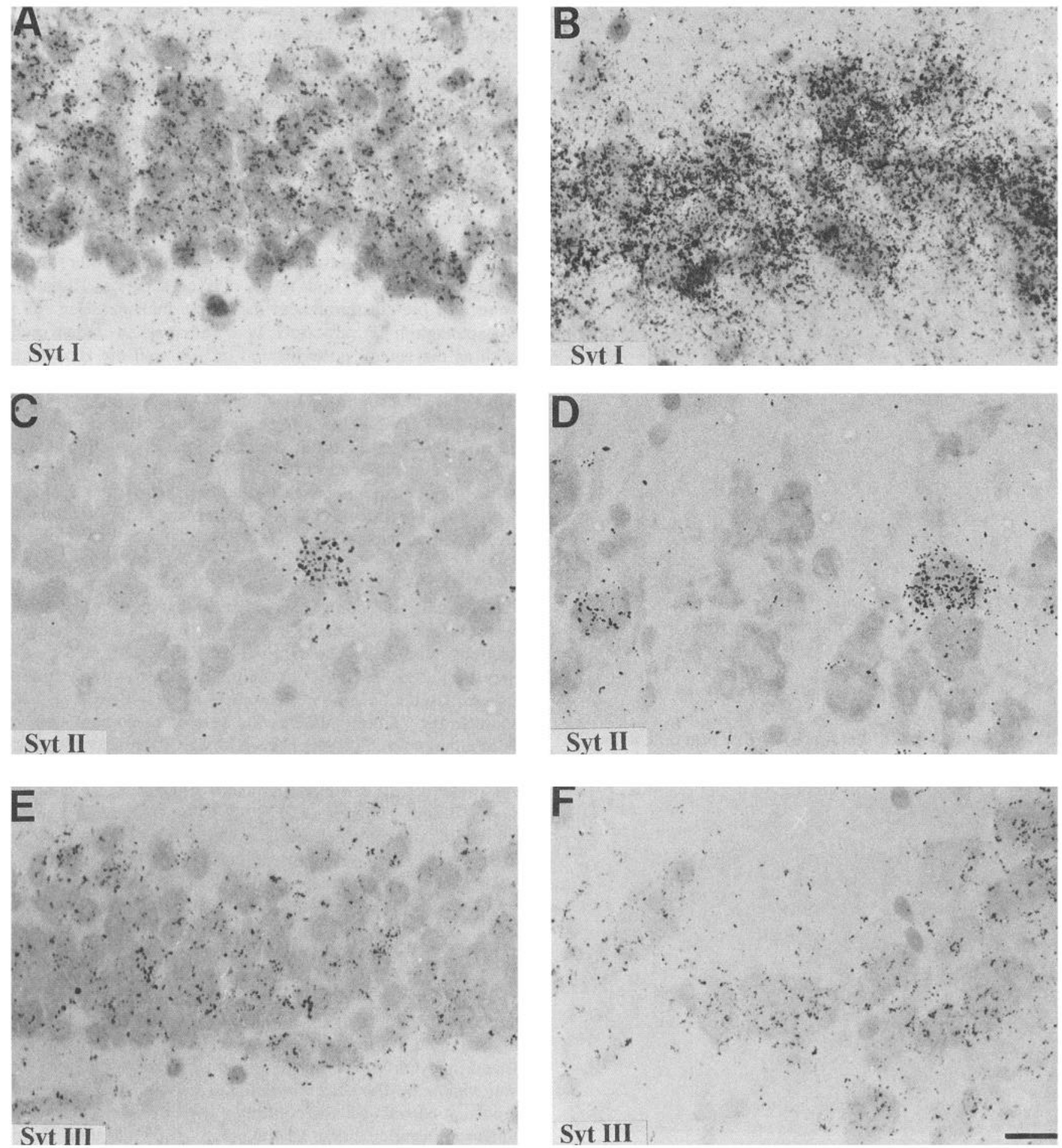

Figure 4. High-power bright-field photomicrographs of the hippocampus through the dentate gyrus $(A, C, E)$ and the CA3 cell layer $(B, D, F)$ illustrating the distribution of synaptotagmin $\mathrm{I}(A, B)$, II $(C, D)$, and III $(E, F)$ transcripts. Exposure times were 7 weeks $(A-D)$ and 10 weeks $(E$, F). Scale bars, $15 \mu \mathrm{m}$.

mogeneous on all cells. No specific signals were detected with synaptotagmin II and III probes (data not shown).

Adrenal gland. Synaptotagmin I-positive cells were confined to the medulla (Fig. $8 B$ ). Some scattered cells were very strongly labeled. Two to four clusters of 2-6 cells were observed in each medullary section. Their size suggests that they are sympathetic ganglion cells described in the rat adrenal medulla (Dellmann and Brown, 1981). No cells were specifically labeled with synaptotagmin II and III probes (data not shown).

\section{Discussion}

These in situ hybridization studies indicate a number of interesting features of the expression of synaptotagmin transcripts in the CNS and in endocrine cells. 

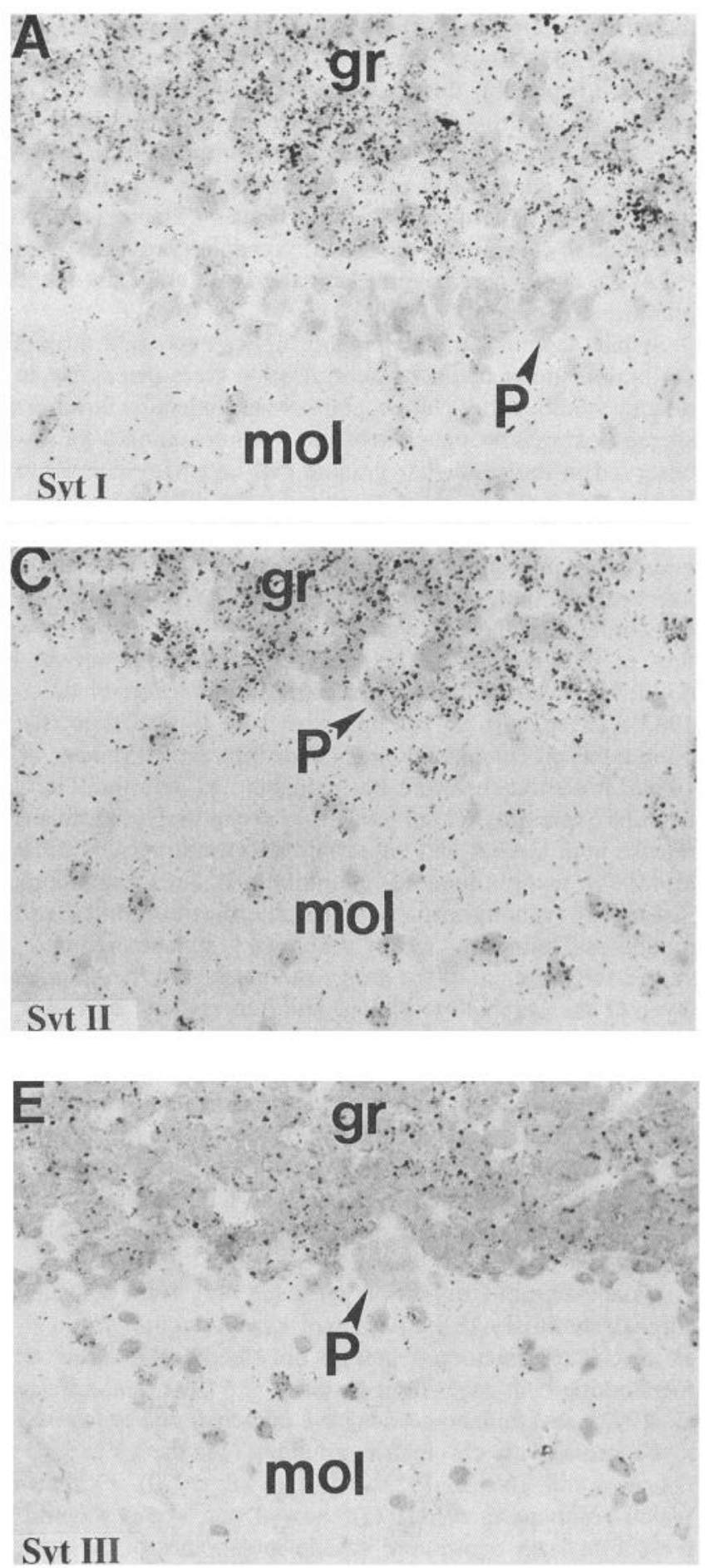
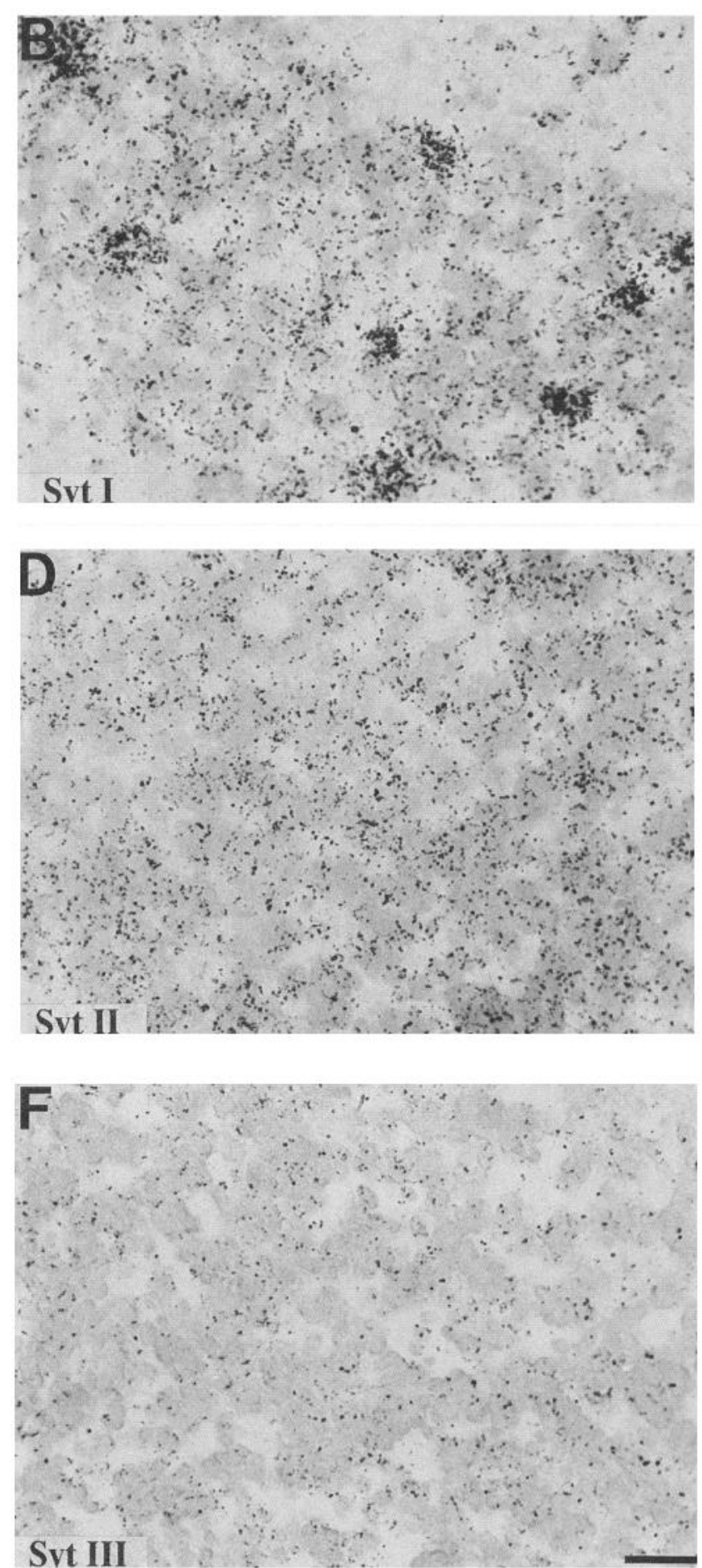

Figure 5. High-power bright-field photomicrographs of the cerebellum through the molecular and Purkinje cell layers $(A, C, E)$ and granular cell layer $(B, D, F)$, displaying the distribution of synaptotagmin I $(A, B)$, II $(C, D)$, and III $(E, F)$ transcripts. gr, granular cell layer; mol, molecular layer; $P$, Purkinje cells $($ arrows $)$. Exposure times were 7 weeks $(A-D)$ and 8 weeks $(E, F)$. Scale bars, $27 \mu \mathrm{m}$.

Three variants of synaptotagmin have been characterized in rat brain, with a relatively low overall identity of amino acid sequence. However, the sequence corresponding to the C-terminal part of the protein thought to contain, in the case of synaptotagmin I, a $\mathrm{Ca}^{2+}$ /phospholipid binding site (Davletov et al., 1993), high-affinity binding sites for the neurexins (Perin, 1994), and the clathrin adaptor AP-2 (Zhang et al., 1994) is well con- served. Synaptotagmin III is more distantly related to the two other variants. It shares the highest homology with o-p65C, one of the three isoforms characterized in the marine ray (Wendland et al., 1991). No differences in functional and biochemical properties between the synaptotagmins have been reported.

In situ hybridization demonstrated that each of the three synaptotagmin genes has a unique expression pattern. The synap- 

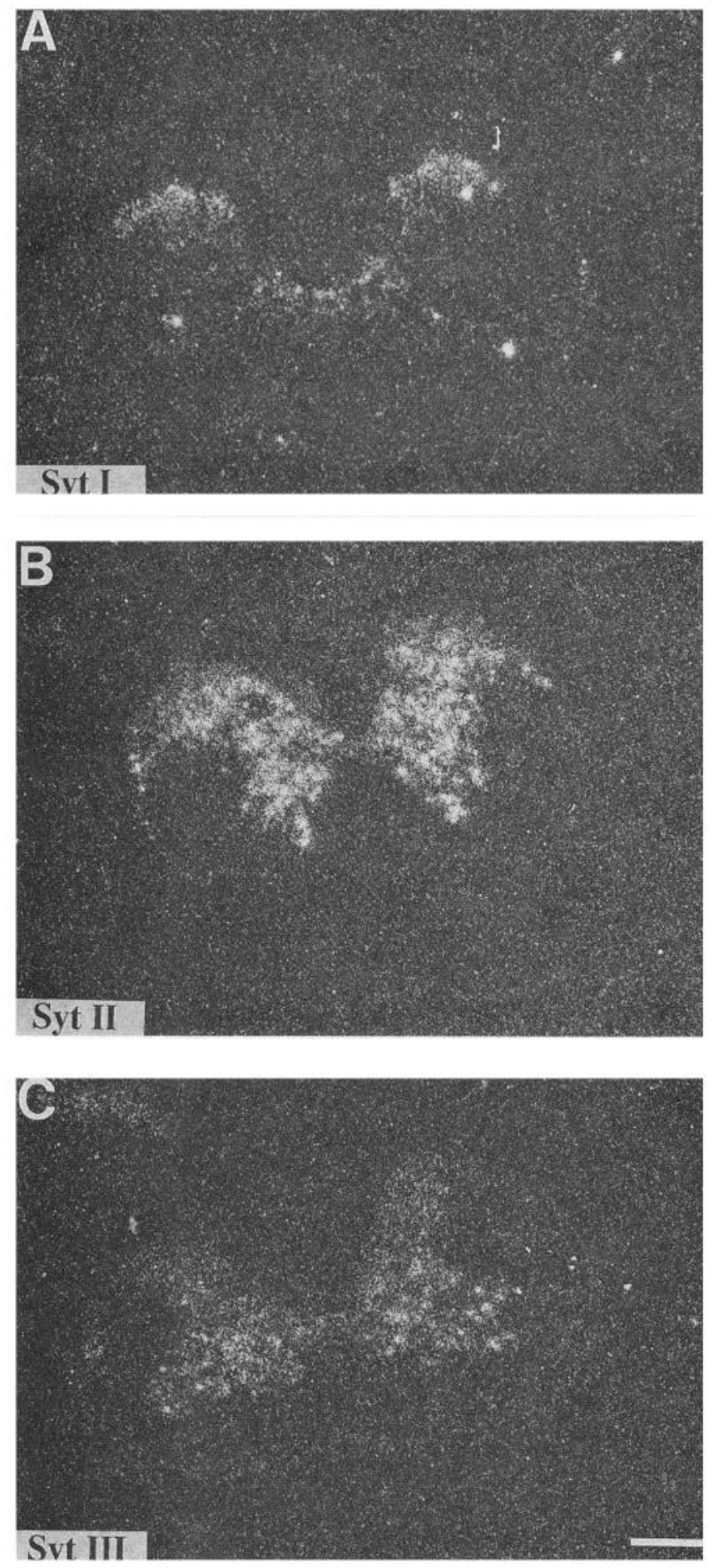

Figure 6. In situ hybridization of synaptotagmin I $(A)$, II $(B)$, and III $(C)$ mRNAs in spinal cord. Sections are oriented with the dorsal horn towards the top of the figure. Exposures were on Kodak X-Omat film for 10 weeks. Scale bars, $0.5 \mathrm{~mm}$.

totagmin III gene is the one expressed in most neurons, but transcripts are much less abundant than the products of the synaptotagmin I and II genes. Among the cells examined, only Purkinje cells were not labeled with synaptotagmin III probes. In the several endocrine cells explored no hybridization signal was visualized. However, occasionally on pituitary sections very weak specific hybridization was detected (data not shown). Al- though Northern blots (Mizuta et al., 1994) suggest that synaptotagmin III mRNAs are expressed in adrenal and pituitary glands, it is possible that the oligonucleotide hybridization method was not sensitive enough to detect very low transcript levels. This study indicates that synaptotagmin I transcripts are the most abundant in adrenal and pituitary glands. It would therefore be interesting to determine if in these tissues synaptotagmin III is preferentially localized on small synaptic-like microvesicles (SLMV), and synaptotagmin I on the more abundant secretory granules.

Synaptotagmin I transcripts are highly expressed throughout the brain. Strong levels of hybridization were detectable in the olfactory bulb, cortex, hippocampus, and thalamus. Striking cellspecific expression patterns of the synaptotagmin I gene were observed in the cerebellar granule cell layer. In addition to the labeling of granule cells, prominent hybridization signals on scattered cell bodies were detected. These patches of silver grains probably correspond to the large perikarya of the Golgi interneurons that synapse on dendrites of numerous granule cells, inhibiting their activation by mossy fibers. A high proportion of Golgi cells are believed to use $\gamma$-aminobutyric acid (GABA) as an inhibitory neurotransmitter (Schulman et al., 1983). The pattern of labeling seen here is similar to that reported for proenkephalin mRNA distributions (Shivers et al., 1986). It should therefore be interesting to determine if Golgi neurons expressing a high number of synaptotagmin I transcripts release both GABA and enkephalins. Interestingly, Matthew et al. (1981), using a monoclonal antibody against a nonidentified isoform of synaptotagmin, and Takahashi et al. (1991), using a monoclonal antibody which recognizes synaptotagmin I, revealed the presence of the antigen in patches in the granule cell layer of the cerebellum which could correspond to Golgi cell synapses on granule cell dendrites.

In the most caudal part of the CNS, weak hybridization signals with synaptotagmin I probes were observed in the brainstem and spinal cord. In this area, only neurons of the dorsal horn are labeled. Our results are in good agreement with Northern blotting data of Geppert et al. (1991), who reported that the distribution of synaptotagmin I mRNA follows a rostrocaudal gradient.

Synaptotagmin I transcripts were the only form detectable in adrenal medullary cells. Although synaptotagmin's role in the exocytosis of secretory vesicles is not clearly established in neuroendocrine cells (see Shoji-Kasai et al., 1992, and Elferink et al., 1993), several laboratories have demonstrated synaptotagmin to be present on chromaffin granules (Matthew et al., 1981; Fournier and Trifaro, 1988; Perin et al., 1990). Furthermore, Walch-Solimena et al. (1993) showed that synaptotagmin I is present on large dense core vesicle membranes of the posterior pituitary. We observed the presence of synaptotagmin I mRNAs in the pituitary gland in agreement with Northern blotting data of Mizuta et al. (1994). They are homogeneously expressed among the anterior and intermediate pituitary cells. Thus synaptotagmin I may be involved in the release of the several peptide hormones from secretory granules. The hybridization level found in the intermediate pituitary was particularly strong. These cells are known to release peptides derived from the pro-opiomelanocortin precursor (POMC). A population of cells that synthesize POMC also occurs in the anterior pituitary, and peptide synthesis in the anterior and intermediate lobes is submitted to differential regulations (Eipper and Mains, 1980). Doublelabeling experiments would allow a comparison of the regulation 

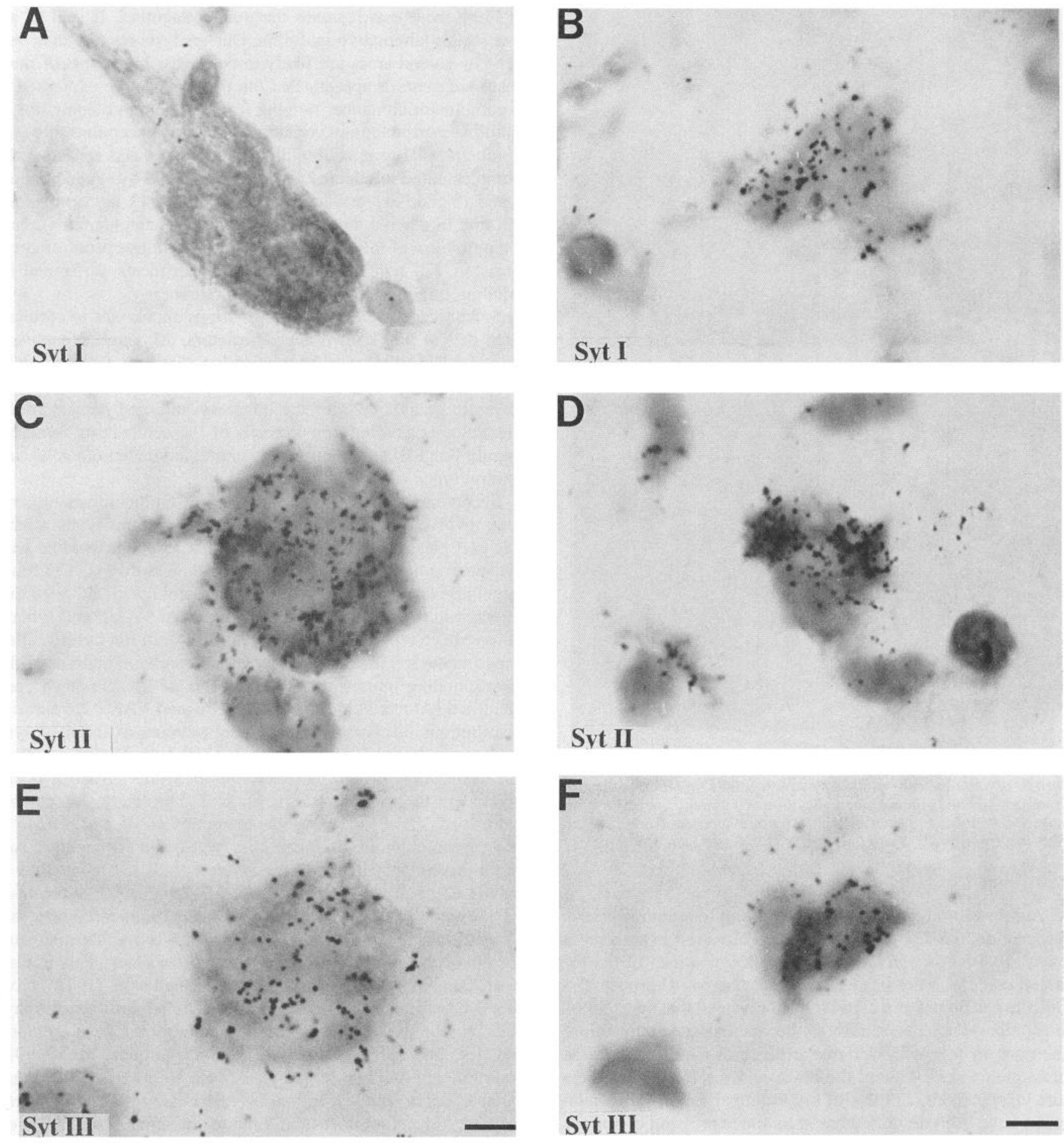

Figure 7. High-power bright-field photomicrographs of the ventral $(A, C, E)$ and dorsal horn $(B, D, F)$ cells of the spinal cord, showing the distribution of synaptotagmin I $(A, B)$, II $(C, D)$, and III $(E, F)$ transcripts. Exposure times were 8 weeks $(A-D)$ and 10 weeks $(E, F)$. Scale bars: $A, C, E, 7 \mu \mathrm{m} ; B, D, F, 5 \mu \mathrm{m}$.

of synaptotagmin I and POMC gene expression in these two populations of cells.

Synaptotagmin II displays a very different pattern of expression. It is the major form in the caudal brain: cerebellum, brainstem, and spinal cord. Similar results were observed by Geppert et al. (1991), who described an inverse gradient of expression for synaptotagmin I and II genes. Synaptotagmin II mRNAs were strongly expressed throughout the entire cerebellum. It was the only form detected in Purkinje cells. An unanticipated finding was that synaptotagmin II mRNAs were found in only subsets of forebrain neurons. In the posterior thalamus, synaptotagmin II transcripts were restricted to the ventral posteromedial, ventral posterolateral, and laterodorsal nuclei. Central regions were not labeled. Synaptotagmin II transcripts were abundant in the reticular thalamic nuclei while synaptotagmin I mRNAs were not detectable. This area appears to contain only one type of 

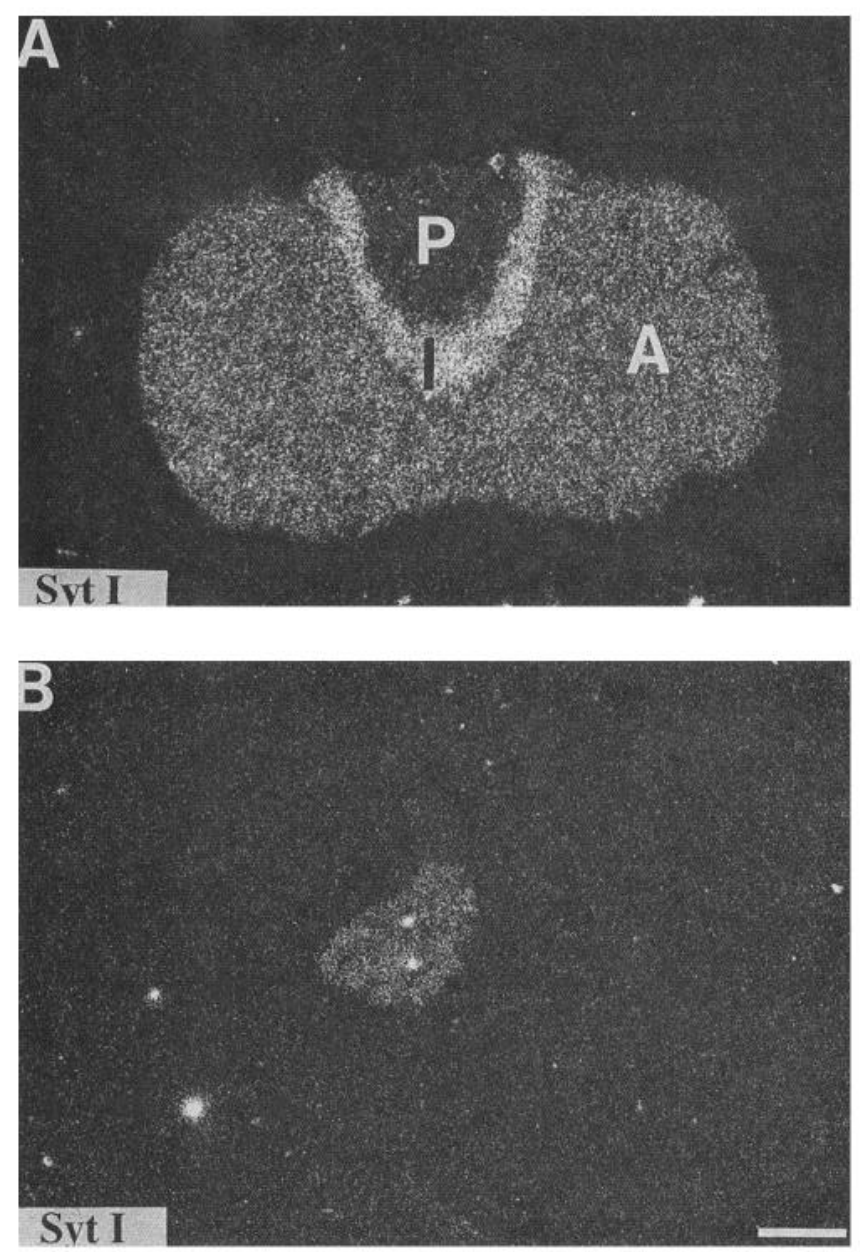

Figure 8. In situ hybridization of synaptotagmin I on sections through the pituitary $(A)$ and adrenal gland $(B)$. Pituitary gland: $A$, anterior lobe; $I$, intermediate lobe; $P$, posterior lobe. Exposure were on Kodak X-Omat film for 8 weeks $(A, B)$ and 10 weeks $(C)$. Scale bars, $0.5 \mathrm{~mm}$.

GABAergic neuron (Jones, 1983) projecting to thalamic nuclei. Neuropeptide Y mRNAs have also been observed in these cells (Morris, 1989). Also, in amygdala only a few nuclei of the basolateral complex were labeled by synaptotagmin II probes. Experiments performed at a cellular level revealed that synaptotagmin II probes distinguish strikingly between discrete populations of neurons in layers IV-VI of the cerebral cortex and in the dentate granule cell region, the hilus, and the CA1-CA3 areas of the hippocampus. Subsets of hippocampal and cortical interneurons have been described based on the expression of various neurotransmitters, neuropeptides, and receptors. More recently, Weiser et al. (1994) labeled scattered neurons throughout the hippocampus with a probe for a specific isoform of a Shawrelated $\mathrm{K}^{+}$channel. Furthermore, transcripts coding for the NR2D subunit of the NMDA receptor show a very similar distribution (Monyer et al., 1994).

In spinal cord high levels of expression are seen in putative motoneurons, demonstrating that synaptotagmin II together with synaptotagmin III may be involved in neurotransmitter release at the neuromuscular junction. No hybridization signals were detectable in the endocrine cells explored. Identical results have been found in the adrenal gland by Northern blots (Geppert et al., 1991) and in PC12 cells (Shoji-Kasai et al., 1992).
From these data it seems that synaptotagmin I, II, and III are not simply alternative isoforms. Our analysis reveals that neurons in several areas are likely to coexpress transcripts of more than one gene. It appears that the three genes are expressed in a combinatorial manner ranging from expression of only one to multiple synaptotagmin variants. With a few exceptions, the synaptotagmin III gene is ubiquitously expressed and appears to be complemented in selected neurons of the CNS by synaptotagmin I and II gene expression; but in Purkinje cells (synaptotagmin II), and in adrenal and pituitary glands (synaptotagmin I), only a single form of mRNAs was detected. Definitive proof of coexpression will require colocalization experiments performed by labeling oligonucleotides with distinct tracers.

Synaptotagmin transcript distributions appear not to correlate with that of any known neuromediators. Although synaptotagmin II mRNAs seem to be confined in discrete, possibly inhibitory interneurons containing GABA, they are absent in GABAergic granule cells of the olfactory bulb and present in the glutamate-containing granule cells of the cerebellum. Synaptotagmin I and III genes are widely expressed in neurons releasing several types of neurotransmitter.

Synaptotagmin appears to be part of a multicomponent complex involved in neurotransmitter release. Several synaptic vesicle and plasma membrane proteins that associate in vitro with synaptotagmin are also present in multiple isoforms. The functional relevance of these variants is also unknown, although differences in interactions between isoforms of VAMP and syntaxin have been reported (Calakos et al., 1994). In situ hybridization experiments have revealed differential expression patterns of the corresponding transcripts. Two isoforms of VAMPs have been identified (Archer et al., 1990). VAMP 1 and VAMP 2 transcript distributions display similar regional patterns to those of synaptotagmin II and I, respectively. VAMP 1 transcripts are present in the most caudal part of the brain while VAMP 2 is expressed in the most rostral areas. It is thus likely that combinations of VAMP 1 with synaptotagmins II-III and VAMP 2 with synaptotagmins I-III mRNAs will occur in neurons. Another protein which associates in vitro with synaptotagmin is SNAP 25. A limited regional SNAP 25 mRNA distribution which has been reported by Oyler et al. (1989) resembles that of synaptotagmin I and III. Synaptophysin is another major integral membrane protein of small synaptic vesicles likely to play a role in neurosecretion (Betz, 1990). Bennett et al. (1992a) have found that synaptotagmin/p65 was associated with synaptophy$\sin / \mathrm{p} 38$ in a large protein complex solubilized from synaptic vesicles. Data from in situ hybridization (Marquèze et al., 1991) and immunohistochemistry (Fykse et al., 1993) have shown that synaptophysin and synaptoporin genes are differentially expressed, resulting in several unique combinations. However, none of these patterns fully match the distribution of synaptotagmin mRNA.

Thus, our results on synaptotagmin transcript segregation will be particularly useful in attempts to identify native multicomponent complexes used by neurons and endocrine cells to perform secretion. It is likely that specific sets of synaptic and plasma membrane protein variants will confer different properties to the synapse. Further studies on colocalization of these various isoforms will be necessary in order to sort out the potential combinations that may be used by individual neurons. Cellular expression of multiple isoforms composing the secretory machinery will require complex genetic control during neuronal development and plasticity that it will be essential to understand. 


\section{References}

Archer BT III, Özçelik T, Jahn R, Francke U, Südhof TC (1990) Structures and chromosomal localizations of two human genes encoding synaptobrevins 1 and 2. J Biol Chem 265:17267-17273.

Bennett MK, Calakos N, Kreiner T, Scheller RH (1992a) Synaptic vesicle membrane proteins interact to form a multimeric complex. I Cell Biol 116:761-775.

Bennett MK, Calakos N, Scheller RH (1992b) Syntaxin: a synaptic protein implicated in docking of synaptic vesicles at the presynaptic active zone. Science 257:255-259.

Betz H (1990) Homology and analogy in transmembrane channel design: lessons from synaptic membrane proteins. Biochemistry 29 : 3591-3599.

Bommert K, Charlton MP, DeBello WM, Chin GJ, Betz H, Augustine GJ (1993) Inhibition of neurotransmitter release by $\mathrm{C}_{2}$-domain peptides implicates synaptotagmin in exocytosis. Nature 363:163-165.

Brose N, Petrenko AG, Südhof TC, Jahn R (1992) Synaptotagmin, a calcium sensor on the synaptic vesicle surface. Science 256:10211025.

Calakos N, Bennett MK, Peterson KE, Scheller RH (1994) Proteinprotein interactions contributing to the specificity of intracellular vesicular trafficking. Science 263:1146-1149.

Davletov BA, Südhof TC (1993) A single $\mathrm{C}_{2}$ domain from synaptotagmin $\mathrm{I}$ is sufficient for high affinity $\mathrm{Ca}^{2+}$ /phospholipid binding. $\mathrm{J}$ Biol Chem 268:26386-26390.

DeBello WM, Betz H, Augustine GJ (1993) Synaptotagmin and neurotransmitter release. Cell 74:947-950.

Dellmann H-D, Brown EM (1981) Textbook of veterinary histology, second edition. Philadelphia: Lea and Febiger.

DiAntonio A, Schwarz TL (1994) The effect on synaptic physiology of synaptotagmin mutations in Drosophila. Neuron 12:909-920.

Eipper BA, Mains RE (1980) Structure and biosynthesis of pro-adrenocorticotropin/endorphin and related peptides. Endocr Rev 1:1-27.

Elferink LA, Peterson MR, Scheller RH (1993) A role for synaptotagmin (p65) in regulated exocytosis. Cell 72:153-159.

Fournier S, Trifaro J-M (1988) A similar calmodulin-binding protein expressed in chromaffin, synaptic and neurohypophyseal secretory vesicles. J Neurochem 50:27-37.

Fykse EM, Takei K, Walch-Solimena C, Geppert M, Jahn R, De Camilli P, Südhof TC (1993) Relative properties and localizations of synaptic vesicle protein isoforms: the case of the synaptophysins. J. Neurosci 13:4997-5007.

Geppert M, Archer BT III, Südhof TC (1991) Synaptotagmin II. J Biol Chem 266:13548-13552.

Hata Y, Davletov B, Petrenko AG, Jahn R, Südhof TC (1993) Interaction of synaptotagmin with the cytoplasmic domains of neurexins. Neuron 10:307-315.

Jones EG (1983) The thalamus. In: Chemical neuroanatomy (Emson PC, ed), pp 257-336. New York: Raven.

Lévêque C, Hoshino T, David P, Shoji-Kasai Y, Leys K, Omori A, Lang B, El Far O, Sato K, Martin-Moutot N, Newsom-Davis J, Takahashi M, Seagar MJ (1992) The synaptic vesicle protein synaptotagmin associates with calcium channels and is a putative Lambert-Eaton myasthenic syndrome antigen. Proc Natl Acad Sci USA 89:36253629.

Lévêque C, El Far O, Martin-Moutot N, Sato K, Kato R, Takahashi M, Seagar M (1994) Purification of the N-type calcium channel associated with syntaxin and synaptotagmin. I Biol Chem 269:63066312.

Littleton JT, Stern M, Schulze K, Perin M, Bellen H (1993) Mutational analysis of Drosophila synaptotagmin demonstrates its essential role in $\mathrm{Ca}^{2+}$-activated neurotransmitter release. Cell 74:1125-1134.

Marquèze-Pouey B, Wisden W, Malosio M-L, Betz H (1991) Differ- ential expression of synaptophysin and synaptoporin mRNAs in the postnatal rat central nervous system. J Neurosci 11:3388-3398.

Matthew WD, Tsavaler L, Reichardt LF (1981) Identification of a synaptic vesicle-specific membrane protein with a wide distribution in neuronal and neurosecretory tissue. J Cell Biol 91:257-269.

Mizuta M, Inagaki N, Nemoto Y, Matsukura S, Takahashi M, Seino S (1994) Synaptotagmin III, a novel isoform of rat synaptotagmin expressed in endocrine and neuronal cells. J Biol Chem 264:1167511678.

Monyer H, Burnashev N, Laurie DJ, Sakmann B, Seeburg PH (1994) Developmental and regional expression in the rat brain and functional properties of four NMDA receptors. Neuron 12:529-540.

Morris BJ (1989) Neuronal localisation of neuropeptide $Y$ gene expression in rat brain. J Comp 290:358-368.

O'Connor V, Shamotienko O, Grishin E, Betz H (1993) On the structure of the "synaptosecretosome." FEBS Lett 326:255-260.

Oyler GA, Higgins GA, Hart RA, Battenberg E, Billingsley M, Bloom FE, Wilson MC (1989) The identification of a novel synaptosomalassociated protein, SNAP-25, differentially expressed by neuronal subpopulations. J Cell Biol 109:3039-3052.

Paxinos G, Watson C (1986) The rat brain in stereotaxic coordinates, 2d ed. Sydney: Academic.

Perin MS (1994) The COOH terminus of synaptotagmin mediates interaction with the neurexins. J Biol Chem 269:8576-8581.

Perin MS, Fried VA, Mignery GA, Jahn R, Südhof TC (1990) Phospholipid binding by a synaptic vesicle protein homologous to the regulatory region of protein kinase C. Nature 345:260-263.

Petrenko AG, Perin MS, Davletov BA, Ushkaryov YA, Geppert M, Suidhof TC (1991) Binding of synaptotagmin to the $\alpha$-latrotoxin receptor implicates both in synaptic vesicle exocytosis. Nature 353:6568.

Schulman AE (1983) Chemical neuroanatomy of the cerebellar cortex. In: Chemical neuroanatomy (Emson PC, ed), pp 209-227. New York: Raven.

Shivers BD, Harlan RE, Romano GJ, Howells RD, Pfaff DW (1986) Cellular localization of proenkephalin mRNA in rat brain: gene expression in the caudate-putamen and cerebellar cortex. Proc Natl Acad Sci USA 83:221-225.

Shoji-Kasai Y, Yoshida A, Sato K, Hoshino T, Ogura A, Kondo S, Fujimoto Y, Kuwahara R, Kato R, Takahashi M (1992) Neurotransmitter release from synaptotagmin-deficient clonal variants of PC12 cells. Science 256:1820-1823.

Söllner T, Bennett MK, Whiteheart SW, Scheller RH, Rothman JE (1993) A protein assembly-disassembly pathway in vitro that may correspond to sequential steps of synaptic vesicle docking, activation, and fusion. Cell 75:409-418.

Takahashi M, Arimatsu Y, Fujita S, Fujimoto Y, Kondo S, Ilama T, Miyamoto E (1991) Protein kinase $\mathrm{C}$ and $\mathrm{Ca}^{2+} /$ calmodulin-dependent protein kinase II phosphorylate a novel $58-\mathrm{kDa}$ protein in synaptic vesicles. Brain Res 551:279-292.

Walch-Solimena C, Takei K, Marek KL, Midyett K, Südhof TC, De Camilli P, Jahn R (1993) Synaptotagmin: a membrane constituent of neuropeptide-containing large dense-core vesicles. J Neurosci 13: 3895-3902.

Weiser M, Vega-Saenz de Miera E, Kentros C, Moreno H, Franzen L, Hillman D, Baker H, Rudy B (1994) Differential expression of shaw-related $\mathrm{K}^{+}$channels in the rat central nervous system. J Neurosci 14:949-972.

Wendland B, Miller KG, Schilling J, Scheller RH (1991) Differential expression of the p65 gene family. Neuron 6:993-1007.

Yoshida A, Oho C, Omori A, Kuwara R, Ito T, Takahashi M (1992) HPC- 1 is associated with synaptotagmin and $\omega$-conotoxin receptor. J Biol Chem 267:24925-24928.

Zhang JZ, Davletov BA, Südhof TC, Anderson RGW (1994) Synaptotagmin $I$ is a high affinity receptor for clathrin AP-2: implications for membrane recycling. Cell 78:751-760. 